\title{
Educate through Debate. The Project "A Suon di Parole"
}

\author{
By Paolo Sommaggio* \\ Alvise Schiavon \\ Marco Mazzocca ${ }^{*}$
}

The paper introduces the educational project on the debate named "A suon di parole". It is a project that started in 2010 following a collaboration between the Faculty of Law of the University of Trento and IPRASE (Provincial Institute for Research and Educational experimentation of the Autonomous Province of Trento, Italy), and over the years the Cities of Trento and Rovereto subsequently joined. This collaborative project aims to develop, in a fun and competitive manner, the ability of high school students to argue and counter-argue. In a healthy debate intended to develop their logic, reasoning and critical thinking. To do this, debate tournaments have been organized, in which intellectual games were played, along with structured arguments and counter-arguments. As a result, it was observed how the dialectical confrontation, lived as a sporting competition, was able to promote in young people the desire and the capacity to compare their own reasoning with those of others in a manner that is not influenced by common teaching methods. Thus, through careful selection of themes for critical debate, an observation was made on how each student, regardless of his/her personal history, has had the opportunity to learn, understand, and, occasionally, change his/her beliefs through the dialectical confrontation with other students. Indeed, the purpose of the game was not to present pre-reasoned formulae to students in order to impose them as a specific way of thinking or speaking, but rather as ways of creating a game field where they are free to intellectually compete with each other. In order to develop the autonomy of students' thinking and, at the same time, increase their integration and social cohesion, teaching took place through the experience of judicial debate in which two parties clash in a simulated court setting and not through lectures. In this way students approached the world of rules (legal, logical and ethical) through a kind of "trial game", thus developing the ability to support their ideas through the oppositional comparison which led us to suggest that the project has achieved its purpose.

Keywords: counter-argumentation, critical thinking, debate, formation, rhetoric.

\section{Introduction}

In everyday life as well as in scientific discourses disagreements (interpreted as a lack of consensus around an assertion) are not only common but often unavoidable. Everyone in their lives tend deal with disagreements at some point so that the ability to engage critically in efforts that seek to reach a consensus is

\footnotetext{
*Associate Professor, University of Trento, Italy.

${ }^{\dagger}$ Research Fellow, University of Bologna, Italy.

${ }^{\star} \mathrm{PhD}$ Candidate, University of Padua, Italy.
} 
quite valuable. One of the ways to deal with disagreements is through debates.

Anecdotal evidence tends to suggest that disagreements result from logical fallacies or faulty logic rather than on the consequence of different representations of facts. In essence, disagreements may be rooted in different and complex reasoning such as ideological, moral or ethical reasoning. Our experience over time suggests that one of the most important challenge today is not to merely recognize and understand the nature of disagreements, but rather to deal with them and in some cases, compose them. This is what pluralistic and democratic societies require from their citizens. This is the reason why, in 2010, the University of Trento and IPRASE (Provincial Institute for Research and Educational Experimentation of the Autonomous Province of Trento) gave birth to an educational route aimed at increasing the democratic consciousness and the aptitude for public discourse through an innovative debating tournament called "A Suon di Parole" (ASP) ${ }^{1}$.

The aim of this paper, therefore, is to introduce the ASP project, to explain the reasons that led to its creation and highlight its unique design features. To do this, in the next section we give some background information about the project in order to provide the rationale that led to its birth and the goals intended to achieve, focusing on its innovative elements compared to others debating tournaments (Tamanini 2014).

In the third section, we produce the format of the tournament. In this regard, we explain the structure of the tournament, the role of each team member, features regarding the way teachers and students are trained and involved, the criteria of judgement and, last but not least, the goals we aim to achieve through the choice of topics. Consequently, in the fourth section we provide and comment on some tournament data in order to empirically show the effects of this particular form of tournament on the formation of students.

Finally, in the last section, we try to draw some conclusions and, at the same time, to predict some possible developments of the project.

\section{General Information about the Project}

In recent years, the wide spread of mass media and social networks has consistently increased the opportunities for people to communicate. This is an unprecedented historical opportunity, since they do not just create connections among people, but allow for the spread of news, ideas and opinions. In other words, they help to create a real virtual public square where anyone is free to express themselves (Dagostini 2013, Dagostini 2010, Cavalla 1992).

However, it must be noticed that if the increased opportunities to communicate opens a number of unforeseeable possibilities, on the other hand it may also represent a hazard to our societies, our democracies, and our

\footnotetext{
1"A Suon di Parole" (literally "to the sound of words") is an Italian wordplay based on the meaning of "A suon di" which can be translate both as "to the sound of" and as "by dint of". Therefore, in this latter sense, the title of the project represents the wish that the debate may be won "by dint of" words, i.e. through the quality of oral speech.
} 
information systems. In fact, no matter how many ideas, opinions, or news are widespread, the issue emerging in our societies, we argue, concerns the way of developing critical thinking around this information abundance. If people can only accept or reject an idea, without being able to rationally justify its merit, they end up exposing themselves as sycophants or bigots rather than critical individuals.

For these reasons we think a tool to develop social, civic and logical argumentative skills is needed in order to call in question assumptions that people make about their world and how it works, and healthy debates can play a meaningful role in that regard (Sommaggio 2012, Iacona 2010, Gilardoni 2008). In the ASP project debating is regarded as a way of testing an assertion by posing critical questions that illuminate assumptions being made in such an assertion. The project attempts to prepare students to face challenges based on the ability to argue and counter-argue on civic and social issues.

It is assumed that even in everyday life when it comes to making a decision which is shared with other people, such a decision often happens to face divergent opinions that give rise to disagreement, which can often escalate into a fight, especially when no one is willing to question its assumptions and merit.

It is on the basis of developing students' critical thinking through debates that the project was mooted. It hoped to generate and stimulate in younger generations a trustful attitude in rational research, in the free comparison of ideas, in the non-violent conduct of discussion, as well as a critical attitude (Fisher 2011, Moore 2011, Freeley 1996, Colbert 1995, Norris 1992, McPeak 1990, Parella 1986) toward their thesis and in that of others, through the concrete practice of building and confronting arguments and counter-arguments.

Furthermore, this project aims to help students to acquire through gaming a deeper awareness of themselves, of their abilities and of their own interests in the merits of rationality. This is made possible because the proposed topics are designed to stimulate students to put forward into the game not only their own ideas but also their concrete experiences and personal opinions. In this way, indeed, the game itself turns from playing activities to an activity of research and rediscovery of the self (Rybold 2006, Wiggins 1993).

Finally, it aims to promote the spirit of collaboration, the teamwork attitude and listening ability. In this sense, one of the purpose of debates that arose during the ASP tournament is to develop the ability to listen and re-elaborate the opinions of others, not only to develop thoughts through oppositions, but also to improve the ability to listen and deeply understand the opinion of others altogether, to get it and to find its criticality.

\section{Special Features of the Project}

Nowadays, there are many possible debate formats (Brown 2017, Davis et al. 2016, Bibby 2014, Quinn 2009). However, none of these formats, currently used in the international debating tournaments, seemed to fit the goals we intended to achieve through the "A suon di parole" project. In particular, what 
we prefigured in the construction of the ASP debate format was the creation of a debate model that is able to avoid the "critical points" of other forms of debate. For this reason, we imagined a model that, first of all, could involve as many students as possible. In fact, in the ASP debate format there are 6 speakers actively involved per team in each match (3 for the arguments phase and 3 for the counter-argument phase).

However, for a more in-depth analysis, the number of real participants for each team should be higher, we argue. Indeed, to facilitate effective use of this approach, the topic of each challenge is communicated to the teams ten days before the match, so every student member of the team can contribute to elaborate the team's thesis. Furthermore, in the construction of counter-argument, all members of the team are involved in the goal of understanding and finding the weaknesses of the other team's thesis, both speakers and who are not speakers in that match. These features of the ASP debate format not only involve in the project as many people as possible, but it pushes teams (which coincides with the class group) to be more co-operative. In fact, by giving a role to all the participants, our observations indicate that it allows all students, on the one hand, to improve their listening speaking skills and, on the other hand, it encourages integration in the group and the personal growth of a student.

Secondly, another important feature of the ASP debate format is its probable suitability to deal with the disagreement (Feldman and Warfield 2010). The entire tournament, from the choice of topics to the concrete structure of matches, is designed to allow the participants to focus on oppositional argument (Prakken 1997), its merit and weakness as analysed through basic tenets of critical thinking such as the perspective, goal, assumptions as well as consequences and implications of argument on improving an intended situation. This would allow the team to develop an improved version of a good argument or pose a counterargument which neutralises a mere dualistic approach to an argument.

Indeed, on one hand, topics are designed in order to make claims maximally oppositional and, at the same time, equivalent. They do not consist of a mere dualistic opposition (pro/counter something), but they should show the common principle behind both claims ${ }^{2}$.

On the other hand, it was established to clearly separate the argumentation phase from the counter-argument phase, unlike most of the other formats of debating tournament where the two activities (argue and counterargue) are conducted concurrently ${ }^{3}$ : while in the first stage of the match each speaker must support his/her team's claim through the construction of a speech that can be persuasive, logically grounded and sufficiently argued, in the latter stage of the match the focus of each discourse will not be the thesis of their own team but, conversely, the claim of the opposite team. In particular, each counterargument (or rebuttal) must refute the arguments expressly put forward by the opponents, without introducing new arguments. Therefore, a generic counter-

\footnotetext{
${ }^{2}$ An example of this kind of topic might be the following: "the defense of common goods is a responsibility of citizens/ the defense of common goods is a responsibility of institutions".

${ }^{3}$ This is, for example, the case of the British parliamentary style in which each speaker is simultaneously in charge of arguing his/her thesis and counter-argue the opponent's thesis.
} 
argumentation against the topic of the opposing team would be not sufficient since it is necessary a precise opposition to the specific arguments put forward by the opponents in the argumentation stage. For this reason, listening to opponent is crucial.

Team spirit, listening skills and ability to face opposing arguments are just some features of the ASP debate tournament. A project that, since 2010 on, had an increasing participation and interest from the promoters and students and that intends, in the future, to improve and advance its research towards the education of new generations.

\section{Project Promoters}

The "A suon di parole" project was born as an experimental pathway, starting from the academic year 2010/2011, by IPRASE (Provincial Institute for Research and Educational experimentation of the Autonomous Province of Trento), the Department of Legal Sciences of the Faculty of Law of the University of Trento and by the high schools "Leonardo da Vinci" and "Galileo Galilei" of Trento. Coordination was handled by IPRASE, while scientific supervision is a prerogative of the Faculty of Law at the University of Trento. However, it should be noticed that, from its second edition (academic year 2011/2012), the tournament benefits from the partnership of the City of Trento - specifically the Department of Culture, Tourism and Youth Council. The project also enjoys the patronage of the Italian Philosophical Society and from the academic year 2016/2017 the partnership of the City of Rovereto.

Project promoters share the ownership and responsibility of the projectrelated initiatives, they agree on the general organizational guidelines and the ways of economic support and funding. To do this, the organization of the tournament is headed by a Coordination Group consisting of representatives of the project promoters, the persons designated by them and the teachers of the high schools of Trentino. The Coordination Group developed the guidelines of the tournament and fixed them into a formal set of rules that regulate the enactment of the tournament. This regulation particularly deals with organisational issues, whereas no rules on argumentative techniques or fallacies are provided, consistently with the general inspiration of the project.

Moreover, as we specify below, it should be noticed how the number of higher schools participating is steadily increasing over the years.

Finally, it should be specified that the group of project promoters is an open group. Indeed, other organizations, institutions, associations and societies can participate in the organization of the tournament.

\section{"A Suon di Parole" Debate Format}

The "A Suon di Parole" (ASP) format of the debate, as already mentioned, is promoted primarily as an educational tool to encourage critical thinking and, at the same time, tolerance for different views. It is consistent with the 
Recommendation of the European Parliament and of the Council of 18 December 2006 on key competences for lifelong learning, the Italian national regulations for the reform of the second cycle of education and the Provincial studies plans of Trentino ${ }^{4}$.

The ASP format particularly accentuates both the role of the team and role of every single speaker within debate. Team members perform individually and are responsible for the success of their speech, but the format requires them to work also together, especially in the phase of counter-argument, to succeed. Therefore, reflecting the format's emphasis on both individual work and teamwork, the team score is the sum of the performance of its members. In addition, individual awards are foreseen for the best speakers.

Variants of the format are currently being explored. Indeed, the length of speeches, the number of speakers, the length of preparation time during the debate, the system of evaluation and the language in which to debate may vary 5 . However, in the continuation of this work, only the original format is referred.

\section{Structure}

In the "A Suon di Parole" format, twelve individuals speak during each debate. Six (three per team) in the argumentative phase and six (three per team) on the counter-argument phase. The debate is composed of 13 parts. Twelve are speeches; the remaining is a period of time of about 20 minutes in which each team, after listening to the arguments of the opposing team, prepares their own counter-arguments. In this period of time, each team can make use of any online or bibliographic resources it prefers. The only help not allowed is that of tutors or any other person outside the team.

The first six speeches are constructive speech in which debaters present their reason for supporting their thesis. The remaining speeches, in the counterargument phase, are devoted to specifically contest the arguments presented by the adversary team in the first phase. In this latter phase, debaters are not allowed to introduce new arguments in support of their position.

Each speaker has three minutes in which to present his/her argument or counterargument (depending on the stage of the match). Thus, each match takes about 56 minutes to which are added a further 15 minutes of time about to allow judges to decide the winning team and the best speakers of the match. So that the whole match should last about 1 hour and 10 minutes.

Topics are generally focused on politics, economics, philosophical and social affairs although they can relate to any subject so long as it contains two

\footnotetext{
${ }^{4}$ In this regard Cf. Recommendation 2006/962/EC on key competences for lifelong learning; Italian National Regulation on "Revision of the Ordinary, Organizational and Teaching of Licei" of 15 March 2010; Italian National Regulations laying down rules for the reorganization of professional institutes of 15 March 2010; Italian National Regulations laying down rules for the reorganization of technical institutes of 15 March 2010; Decree of the President of the Province of Trento of 5 August 2011, $\mathrm{n}^{\circ}$. 11-69.

${ }^{5}$ In this regard, two slightly different ASP formats are currently being studied. One in English called "Word Games" and one in German called "Wortbewerb". These latter differ from ASP format not only for the language in which it is debated, but also for slightly different rules.
} 
reasonable and maximally opposites position. Topics are delivered to teams ten days before the match in order to give each team time to study the topics, outline the strategy and prepare the argumentative phase.

Roles

From the beginning one of the ASP format goals was to involve as many people as possible in each match in order to increase the teamwork of each class. Since each team consists of class members, we wanted to increase the integration of members of a class through a playful and educational activity. Indeed, the latter has been able to achieve this goal thanks to the following division of roles:

- Speaker of the arguing phase. The roles of the first six speakers are similar to those in many other formats; they build cases, propose their reasons and justify their arguments. However, on the other hand, in the ASP format speakers of the first phase do not deal with rebuttal to the opposing theses. This explicit exclusion of reply speeches in the first phase creates an interesting dynamic situation. Indeed, if, on the one hand, speakers of first stage are generally free to create and build their argumentative discourses as best they believe. On the other hand, they will have to be careful to make their speeches as unassailable as possible since, having no feedback in this first phase, they do not even have the opportunity to "correct" their saying.

- Speaker of the counter-argument phase. As already mentioned, the importance of counter-argument speakers is crucial. This is because, since their speeches are less "prepared" and, in a way, more spontaneous, they can bring out students' unexplored qualities. Indeed, since every form of new argument is forbidden at this stage, students can only tackle arguments opposed to their claims, consider them and, above all, address them in order to "overcome" them. In other words, it is at this stage that you learn how to deal with disagreements.

- Critical listeners. This is an unofficial role that has arisen in the practice of the matches. Indeed, since the first matches, it was possible to notice how each team involved not only the speakers but also the other classmates in the formulation of counter-arguments. These latter, while not having an active role, helped their classmates take notes during the first phase in addition to having help the speakers of the second stage to prepare their own speeches. Therefore, it is also fair to recognize the fundamental role of these students. 


\section{Important Features}

\section{Training}

One of the key aspects of the ASP debate tournament is certainly in the formation of the teachers and students involved in the project.

Formation is carried out under the responsibility of the Coordination Group: training does not consist in frontal lessons, but rather an informal approach of few hours in which teacher and students are invited to participate is preferred.

In these training hours, the tournament rules are illustrated and brief information are given about the most important argumentation techniques: notwithstanding, trainers tend to highlight the spontaneous ability of students to argue and debate rather than provide a set of abstract rules and prohibitions. That's also the reason why students and teachers are invited to participate in a simulation of a match: we think that the best way to learn skills related to the ASP debate format, is to play the debate.

\section{$\underline{\text { Player's Autonomy }}$}

"A suon di parole" encourages student to be independent of teachers. Indeed, although each team must indicate one or more teachers who will have the function of tutor in the tournament, they can not be helped by their tutors during matches.

Therefore, tutors simply follow the training of students, guarantee internal workouts (which must be self-mastered by students) and accompany the team to the matches.

Organization of the team, workouts and the role of every single student are decided by the class students itself. It will also be up to the class to decide whether to confirm or change the various speakers during the tournament.

\section{Adjudication}

Adjudicators in ASP base their decision on the argumentation and counterargumentation introduced in the course of the debate.

They judge each speaker individually. Therefore, it will be the sum of the votes of each speaker to determine the team result. There are 6 criteria in which each speaker is evaluated and, for each criterion, each adjudicator can give a score of 1 to 5 with 5 representing the highest score and thus superior argumentation.

Moreover, because the focus of the ASP format is on the education, structure is generally important as communication style. ASP debates are always judged by at least three independent adjudicators strangers to the teams involved in the match. Judges make their own judgement according to the following assessment criteria. 


\section{Content of Speech}

- Argumentative quality. It weighs the ability of the speaker to bring useful arguments for discussion. Each speech should possibly be coherent, sufficient, convergent and resistant. Further, they should also be able to overcome others' thesis.

- Coherent. It indicates a link of non-contradiction among premises and the conclusion, which the speaker wants to bring in support of his/her position.

- Sufficient. It represents the reasons necessary to reach the conclusion

- Convergent. It is a logic connection that manifests itself when the different reasons are directed towards the same conclusion

- Resistant. It is the aptitude of the exposed arguments to be unbreakable.

- Argumentative quantity. The number of arguments, data, and sources that each speaker uses to support his/her thesis

- Relevance. It is the relation of a speech to the specific subject of the discussion

$\underline{\text { Mode and Forms }}$

- Exposure Lucidity. Clarity in the exposition; ordered concatenation of arguments

- Dictionary. Language skills; Ability to master the language in which the debate is held (including, where appropriate, technical languages)

- Acting. It is the effectiveness of performance in scenic, persuasive and rhetoric way. In other words, it is the ability to engage the audience (through, for instance, the tone of voice, the posture or the use of spirit jokes)

\section{Data}

Since "A Suon di Parole" is still being developed, in the last few years it was decided to monitor its progress. In this regard, it was decided to collect some data that, in our opinion, can provide useful information in order to measure the effectiveness of the project.

Therefore, starting from the academic year 2012/2013 we started collecting the following data: 
- the number of schools participating in the ASP debate tournament;

- the number of classes participating in the ASP debate tournament (including classes who, while not participating in the "final stage of the tournament", participated in the internal matches ${ }^{6}$ );

- the number of students participating in the ASP debate tournament;

- the number of teachers participating in the ASP debate tournament;

- the number of topics presented during the tournament

The obtained results are shown in the following table:

Table 1. A Selective List of Data regarding the ASP Project

\begin{tabular}{|l|c|c|c|c|c|}
\hline $\begin{array}{c}\text { Academic } \\
\text { Year }\end{array}$ & $\mathbf{2 0 1 2 / 2 0 1 3}$ & $\mathbf{2 0 1 3 / 2 0 1 4}$ & $\mathbf{2 0 1 4 / 2 0 1 5}$ & $\mathbf{2 0 1 5 / 2 0 1 6}$ & $\mathbf{2 0 1 6 / 2 0 1 7}$ \\
\hline Schools & 6 & 7 & 10 & 11 & 12 \\
\hline Classes & 36 & 33 & 35 & 45 & 50 \\
\hline Students & 700 & 620 & 700 & 980 & 1000 \\
\hline Teachers & 100 & 100 & 160 & 200 & 200 \\
\hline Topics & 37 & 27 & 45 & 61 & 53 \\
\hline
\end{tabular}

With reference to the participation to the tournament, the trend seems to be very positive. Indeed, despite some slight drop in the number of classes and students which participated in the tournament in the academic year 2013/2014, the trend seems to increase steadily. More and more high schools, classes and teachers, year after year, decided to join "A Suon di Parole" project.

For this reason, in the coming years, our research will be developed along three different paths:

1. Questionnaires will be given to teachers of the classes involved in the debate tournament (at the beginning and at the end of the tournament). The latter aim to verify the presence of changes in the students' social behaviour.

2. Questionnaires will be given to students of the classes involved in the debate tournament (at the beginning and at the end of the tournament). The latter aim to verify not only the presence of a generic interest in the project, but also the influence of the ASP debate tournament on future student choices.

3. We will collect student report cards before and after the tournament in order to see if there are significant changes in student performance to the oral exams.

\footnotetext{
${ }^{6}$ Indeed, given the large number of classes which wanted to participate in the project, many schools organized internal match in order to decide which classes could participate in the ASP debate tournament.
} 


\section{Conclusion}

Currently in the world there are many forms of debate tournaments. None of these, however, seems able to develop in the younger generations the skills and abilities that ASP debating format may develop.

As we have seen, it is mainly characterized by the presence of an exclusively counter-argumentative phase. The latter, indeed, allows us to evaluate students not only for what they prepare before the match (which is what happens instead for the argumentative phase), but also and especially for what they do during the match.

To be honest, what students face in the match is nothing more than a disagreement. Nevertheless, what happens during the match is fascinating. In fact, through the dialectical confrontation it is possible to notice how students firstly learn the art of listening to their competitors. Subsequently, they will try to understand the views of their opponents. This is because, the goal of the challenge is trying to overcome each other arguments.

Fair play, listening skills, ability to think critically are capabilities that, in concrete terms, allow future generations to become critical, thinking and socially active citizens. Citizens who prefer the dialectic confrontation to violence, reasoning to insult.

In other words, citizens who do not want to overwhelm others but who simply overcome disagreements by dint of words or, in Italian, "A suon di parole".

\section{References}

Bibby N (2014) Discovering the world through debate: a practical guide to educational debate for debaters, coaches, and judges. New York: International Debate Education Association.

Brown Z (2017) The use of in-class debates as a teaching strategy in increasing students' critical thinking and collaborative learning skills in higher education. Educational Futures 1(7). Retrieved from http://bit.ly/2E7r2mb.

Cavalla F (1992) Topica giuridica [Legal topic]. Enciclopedia del Diritto, 720-739. Milano: Giuffrè.

Colbert K (1995) Enhancing critical thinking ability through academic debate. Contemporary Argumentation and Debate 16: 52-72.

Dagostini F (2010) Verità avvelenata. Buoni e cattivi nel dibattito pubblico [Poisoned truth. Good and bad in public debate]. Torino: Bollati Boringhieri.

Dagostini F (2013) Logica in pratica. Esercizi per la filosofia ed il ragionamento comune [Logic in practice. Exercises for philosophy and common reasoning]. Roma: Carrocci editore.

Davis KA, Zorwick MLW, Roland J (2016) Using debate in the classroom: encouraging critical thinking, communication, and collaboration. New York: Routledge.

Feldman R, Warfield TA (2010) Disagreement. Oxford: Oxford University Press.

Fisher A (2011) Critical thinking: an Introduction. Cambridge: Cambridge University Press.

Freeley AJ (1996) Argumentation and debate: critical thinking for reasoned decision making. Wadsworth: Belmont. 
Gilardoni A (2008) Logica e argomentazione: un prontuario [Logic in practice. Exercises for philosophy and common reasoning]. Milano-Udine: Mimesis.

Iacona A (2010) L'argomentazione [The argument]. Torino: Einaudi.

McPeak J (1990) Teaching Critical Thinking: Dialogue and Dialectic. New York: Routledge.

Moore T (2011) Critical thinking and language: The challenge of generic skills and disciplinary discourse. London-New York: Continuum.

Norris S (ed) (1992) The generalizability of critical thinking: Multiple perspectives on an educational ideal. New York: Teachers College Press.

Parella J (1986) The debate method of critical thinking. Dubuque, IA: Kendall Hunt.

Prakken H (1997) Logical Tools for modelling legal arguments: a study of defeasible reasoning in Law. Dordrecht: Kluwer.

Quinn S (2009) Debating in the world schools style: a guide. New York: International Debate Education Association.

Rybold G (2006) Speaking, Listening and Understanding. Debate for non Native English Speakers. New York: International Debate Education Association.

Sommaggio P (2012) Contraddittorio, giudizio e Mediazione [Contradictory, Judgment and Mediation]. Milan: Franco Angeli.

Tamanini C (2014) Il Torneo argomentativo "A Suon di Parole". Caratteristiche e valutazione dell'esperienza, una iniziativa trentina [The "A Suon di Parole" Argumentative Tournament. Characteristics and evaluation of the experience, a thirty initiative]. Istituto Nazionale di Documentazione Innovazione e Ricerca Educativa. Retrieved from http://bit.ly/2EbnACV.

Wiggins G (1993) Assessing student performance: Exploring the purpose and limits of testing. San Francisco, CA: Jossey-Bass. 